\section{EUGENIO ÍMAZ Y LA GUERRA CONTRA LA GUERRA}

\author{
Antolín Sánchez Cuervo \\ Inst. de Filosofía-CCHS. \\ Consejo Superior de Investigaciones Científicas \\ C/ Albasanz, 26-28. 28039 Madrid \\ ascuervo@ifs.csic.es
}

\begin{abstract}
Eugenio Imaz was one of the philosophers of the Spanish exile of 39 that greater attention devoted to criticism of fascism and his warmongers implications. On the horizon of the Spanish war, appealed in this regard to the commitment of the intellectual opposite the barbarism as a touchstone of any radical philosophical experience, outlined a modern genealogy of Nazi-fascism and identified the suicidal ideological contradictions of the liberal European democracies.
\end{abstract}

KEY WORDS: War; Spain; fascism; modernity; humanism.

1. Pocas obras filosóficas del exilio español republicano del 39 sufrieron -y absorbieron, hasta sus últimas consecuencias- el impacto de la guerra y de sus consecuencias como la de Eugenio Ímaz. Pocos intelectuales como él la afrontaron con tanta dignidad e indignación, desplegando al mismo tiempo en torno a ella una jugosa reflexión sobre la crisis de su tiempo. Como reconociera su compañero de exilio José Gaos, "Ímaz figura a la cabeza entre los españoles que sintieron y sienten aún con más intensidad la guerra y se esforzaron y siguen esforzándose por pensarla con más honradez y públicamente" (Gaos 1990, 127). Ciertamente, al hilo de su exilio en México, su pensamiento, entrecortado y lúcido, rocoso y mordaz, concentrará un potencial crítico y adquirirá un tono de denuncia que desbordan los límites de lo que sólo superficialmente podría denominarse una "cuestión española", para señalar toda una constelación de motivos, referencias e hilos conductores implicados entre sí. La quiebra de Europa, y con ella de la misma racionalidad moderna que la alimentara durante siglos, adquiere una actualidad catastrófica bajo

\section{EUGENIO ÍMAZ AND WAR AGAINST WAR}

RESUMEN: Eugenio Ímaz fue uno de los filósofos del exilio español del 39 que mayor atención dedicó a la crítica del fascismo y de sus implicaciones belicistas. En el horizonte de la guerra española, apeló en este sentido al compromiso del intelectual ante la barbarie como piedra de toque de toda experiencia filosófica radical, esbozó una genealogía moderna del nazi-fascismo y señaló las suicidas contradicciones ideológicas de las democracias liberales europeas.

PALABRAS CLAVE: Guerra; España; fascismo; modernidad; humanismo.

la experiencia del fascismo y en la inhibición de las democracias occidentales para hacerle frente, saldándose todo ello con el sacrificio de una república entera. "¿Trataremos de buscar la explicación de nuestro fracaso en nuestra singularidad, en nuestro casticismo, y nos consolaremos de ese fracaso con las promesas ultraístas de esa singularidad?" -se preguntaba en este sentido en 1940, nada más iniciado su exilio- "¿Y si buscáramos las razones de nuestro fracaso en el Comité de No-Intervención, por ejemplo?" (Ímaz, 1992, 61).

Si para Ímaz toda guerra civil es una "microhistoria" en el que "el hombre vive y comprende la historia entera con una intensidad y una condensación únicas" (54), la de España fue una "lucha civil internacional" (63) y hasta una "guerra quijotesca por el hombre universal" (Ímaz, 1988b, 54). Es decir, más allá de tantos tópicos sobre las "dos Españas" o sobre el cainismo y el atraso hispánicos, la guerra española supuso para Ímaz un acontecimiento decisivo para la cultura occidental en medio del que ésta 
desahogó su barbarie latente, largamente incubada a lo largo de una modernidad en la que el hombre universal del Renacimiento se fue pediendo asimismo, reencontrándose sólo bajo el "simulacro" imponente pero trágico de los sistemas filosóficos (1988b, 110).

2. La respuesta de Ímaz a la guerra española es por tanto densa, si bien fragmentada a lo largo de sus numerosas colaboraciones en revistas tan significadas como Cruz y Raya y Diablo Mundo, y, ya en el exilio, España peregrina. Bajo una primera aproximación, lo que esta respuesta trasluce de una manera más inmediata es la denuncia como imperativo primordial de la tarea intelectual. Es la experiencia concreta de la injusticia más que cualquier pregunta teórica -en este caso el paso por las armas de la legitimidad y legalidad republicanas-, lo que da un sentido inmediato a nociones como las de verdad y de subjetividad; lo que sustenta, en primera instancia, toda autoridad moral y política. La denuncia es por tanto la primera condición de un pensar responsable y comprometido con su tiempo, si es que no del mismo pensar en cuanto tal. Éste es al menos el mensaje que se desprende de sus artículos de 1940 en España peregrina. En "Discurso in partibus" (1992, 53-58), "Dos libros de María Zambrano" (59-61), "Pensamiento desterrado" (62-66), "Entre dos guerras" (67-73), "A la luz de la guerra relámpago (1)" (77ss) o "A la luz de la guerra relámpago (2)" (84-89), Ímaz se muestra sobre todo como un testigo, una víctima y un superviviente de la guerra, que da cuenta de ella en primera persona. "Soy un desterrado, un refugiado político. Soy un hombre. Nada menos que todo un hombre, que ésta es la distinción singular que a los sin patria nos hace el país que nos acoge", escribe en este sentido en "Pensamiento desterrado". "Uno entre los demás" - prosigue- cuyo oficio "es de escritor" y cuyo deber "como escritor, será, pues, no traicionar, en el escritor, al nombre" (62).

Precisamente la traición al hombre bajo construcciones discursivas o abstractas de la subjetividad, la traición a la condición humana en su expresión irreductible -aquella que se hace visible a la intemperie del exilio- es lo que para Ímaz delataría a una escritura académica o a un saber de cátedra. Es decir, a todo conocimiento que, racionalizando o eludiendo la guerra, se haga cómplice de ella. De ahí la insatisfacción de Ímaz con "esas dos filosofías que fueron nuestro alimento espiritual en España antes de la guerra: el neokantismo primero y la fenomenología después. Porque son filosofías académicas, centradas técnicamente en un solo problema: la teoría del conocimiento." Problema del que "han descendido a los demás campos de la actividad humana, y han descendido, como es natural, robinsonescamente (...)" (66). Ímaz reivindica así la capacidad de escándalo ante la barbarie como piedra de toque de la experiencia filosófica, frente a la objetividad aséptica de una reflexión "pura" o metafísica que pretende resolver los problemas humanos a partir de construcciones trascendentales ajenas a la realidad sangrante que le envuelve y más o menos deudoras del paradigma epistemológico de la ciencia -esto es, un sujeto frente a un objeto-. Por eso el intelectual, lejos de asemejarse a un héroe robinsonesco del pensamiento que pone la realidad entre paréntesis despojándola de toda inclemencia pasajera o contingente y que reduce todo testimonio subjetivo a un prejuicio o una "doxa" de la que es necesario desprenderse como si se hallara en una isla desierta, está llamado a pensar desde los escombros. Por eso "nosotros buscamos, al revés, una teoría del conocimiento, de la conciencia, que surja de la realidad social que nos rodea, que nos señale el camino para resolver los problemas que su bancarrota nos plantea (...)" (66) ${ }^{1}$. ¿Una teoría vitalista como la de Ortega, misma que -recordemos- empezara a despejarse a partir, precisamente, del abandono de tempranas posturas neokantianas? Tampoco. "¿Qué es eso de la vida? ¿Acaso la razón vital? -se pregunta Ímaz- "Cuando oigas hablar de la razón vital sopla, a ver si se animan los rescoldos" (61).

El vitalismo orteguiano también fue alimento espiritual en tiempos de paz y flaqueza corporal en tiempos de guerra. Aun poniendo el acento en la experiencia singular del hombre concreto, liberándolo así de las abstracción idealista y de la cosificación positivista, no llegó a asumir la experiencia humana de la guerra ni su presencia latente en el meollo mismo de la civilización. Desarrolló una teoría del conocimiento surgida del trajín vital que envuelve al individuo, pero escasamente vigilante ante la latencia de la barbarie en la cultura, incluso bajo sus expresiones más refinadas. Eludió el heroísmo robinsonesco para reemplazarlo por un heroísmo deportivo, según su conocida metáfora de la vida como deporte, y si bien es cierto que otras metáforas suyas no menos célebres como la del naufragio dan al traste con cualquier filosofía de tierra firme, la razón vital siguió siendo una noción académica cuyo fuelle apenas alcanza para reanimar los rescoldos de la guerra. 
Ímaz no discute con Ortega, pero dista mucho de satisfacerse con una experiencia vital en términos olímpicos o académicamente autocomplacientes. En 1940, la vida se revela, sobre todo, como una experiencia desequilibrada por el primado de la guerra. De alguna manera, Ímaz se inscribe en la órbita schmittiana que levanta acta de ese primado, largamente gestado a lo largo de la modernidad a partir de referencias tan capitales como la de Hobbes². La amenaza de la guerra es entonces el eje sobre el que pivota toda política, tanto en la teoría como en la práctica, tanto hacia adentro como hacia afuera del Estado. Ahora bien, Ímaz se inscribe en esta órbita en unos términos diametralmente opuestos a los schmittianos: si la guerra es la experiencia crucial de nuestro tiempo, habrá entonces que pensar la política a contrapelo y no en función de ella. De ahi su pacifismo beligerante, "militante y defensivo, que arrostra la guerra contra la guerra" (67), acorde con un humanismo que elude el pesimismo antropológico de la guerra como estado natural. Para Ímaz, ésta no puede ser obviada por ningún pensamiento responsable y hace mella en toda reflexión en torno a la vida, especialmente en momentos críticos como el de su tiempo, pero no por ello es antropológicamente esencial o necesaria. No lo es, aun cuando la cultura y la civilización se impregnen de ella o, la justifiquen al amparo del saber académico. De ahí en cualquier caso -afirma- "mi paso firme de hombre de letras rehecho por la guerra" que ni "filósofos" ni "maestros" ni "sociólogos" ni "estudios ni demostraciones nuevos" podrá trabar, puesto que "la verdad que me sostiene es hija de la pasión más clarividente. La pasión, en mí, de la verdad de mi pueblo. Escandalosa verdad apasionada. Única verdad, ahora me doy cuenta, que he poseído en mi vida y que, por eso, me posee"; de la que "tendrán que salir las demás, todas las demás, las altas y las bajas" (62s); y al trasluz de la cual se evidencian, además, todos los engaños, pues esa "verdad escandalosa mía, la que me enseña la traición cometida con mi pueblo" -prosigue-

"es ésta: me han engañado, nos han engañado. No sé quién. Pero nos han engañado. Engañado en la escuela, engañado en la iglesia, engañado en la familia, engañado en los periódicos. El engaño es tan inmenso, tan total y sin resquicio, que hasta el manto que lo cobija, el lenguaje, se desdice y me engaña, nos engaña. Dice orden y quiere decir todo lo contrario; amor al pueblo, y todo lo contrario; espiritualismo, y todo lo contrario; civilización, y todo lo contrario; paz, y todo lo contrario, etc., etc. (...) A la verdad la llamaremos, pues, mentira. Mentira a esa verdad que se expende en los centros más acreditados. Mentira a la verdad de cátedra. (...) Mentira a la verdad que nace partenogenésica de los libros, mentira a la verdad que se anuncia como estática adecuación entre el pensamiento y las cosas y que se denuncia por su etérea esquivez cuando el hombre la implora" (63)

Con un tono muy similar comenzaba su "Discurso in partibus":

\begin{abstract}
"Vengo en representación de mí mismo. Quiero decir: que vengo a decir la verdad que llevo dentro, la verdad que nuestra guerra me metió en las entrañas. Ya veis: un intelectual que lleva la verdad en las entrañas, y no en la cabeza, y una verdad que le metieron, no que él se haya fabricado. ¿Puede haber algo más absurdo, con pretensiones de intelectual? Pues este absurdo es lo que vengo a defender. No sé si acertaré a exponer aquella idea que el estallido de la guerra civil me fulguró con una claridad pasmosa: que la verdad no está en el cielo, poblado de intuiciones, sino en la tierra, en esta tierra que piso, junto a mí, y que esta verdad hay gentes que me la quieren arrebatar" (53).
\end{abstract}

Si la guerra y el exilio son experiencias humanas radicales que toda teoría del conocimiento habrá de recoger y asumir si no quiere traicionarse a sí misma, el oficio del intelectual no será otro, entonces, que responder a estas experiencias con toda la beligerancia de su pensamiento. Por eso al intelectual responsable "le es imposible estar au dessus de la mélée", pues el "que se pone en medio" -afirma İmaz, señalando a los de la "tercera España"- "no es intelectual ni hombre, es el pajarito en la máquina neumática que hinca el pico por falta de aire". La misma falta de aire, en definitiva, que apenas daba para animar un montón de rescoldos.

3. Son puntuales, aunque nada casuales ni retóricas, las alusiones de Ímaz al "pueblo", el cual se hacía presente en algunas de las citas anteriores como verdadero antagonista del saber de cátedra y de su complicidad con la guerra. El pueblo, "con su profunda ignorancia, instruida sangrienta y eficazmente por la guerra, por la política" (56) asoma en estos escritos de Ímaz como la referencia inmediata del intelectual escandalizado ante la injusticia, vigilante ante el engaño del lenguaje y ante la barbarie latente en la cultura, y comprometido con una concepción democrática de esta última. Por eso "el pueblo español" era el único que, 
en medio de la guerra, "decía la verdad, la sentía en su raíz y daba consecuentemente testimonio de ella" (67). El pueblo asoma así, de alguna manera, como el sujeto veraz de la historia y el soplo constante de una vitalidad que, al no encogerse bajo ninguna definición académica, afronta la guerra a pecho descubierto. No es una suerte de "espíritu" a la manera de un "Volkgeist" tardo-romántico -que Ímaz identificará más bien con el nacionalismo fascista, como más adelante veremos-; ni un sujeto revolucionario en clave marxista ${ }^{3}$; ni tampoco, obviamente, una "masa" a la que las élites ilustradas de turno están llamadas a educar sin más. Sería más bien el "nosotros" que sustenta al "yo" del testigo indignado, aquello que da sentido a una universalidad enraizada en la tierra, la piedra de toque de toda autenticidad reacia a la invención discursiva, y el sujeto anónimo de una historia escamoteada por las ideologías dominantes.

Las apelaciones de Ímaz al pueblo invitan en este sentido a pensar en toda una constelación de referencias cercanas: la intrahistoria unamuniana, el "comunismo" religioso de Machado y la asimilación que de este último hizo Zambrano a propósito, precisamente, del advenimiento de la República y de su sacrificio bajo la guerra: en su obra autobiográfica Delirio y destino. Los veinte años de una española, por ejemplo, el pueblo sería el sujeto de toda una pleamar en la historia de España, caracterizada por la emergencia de una autenticidad velada durante siglos bajo el protagonismo de gestas imperiales, intrigas cortesanas y ordenanzas eclesiásticas, entre otros acontecimientos enajenantes, en íntima complicidad con la generación intelectual de 19304. Buena muestra de ello la célebre evocación zambraniana de aquellos "hombres pequeñitos españoles, indigenas", agolpados en la Puerta del Sol el 14 de abril de 1931, entre los que podía verse "a uno de ellos con abierta camisa blanca y brazos abiertos, gritando vivas a la República", como un fragmento vivo de "los fusilamientos pintados por Goya" (Zambrano, 2004, 677). Precisamente el descamisado de esta pintura había sido evocado por la propia Zambrano en Pensamiento y poesía en la vida española -uno de sus primeros escritos del exilio-, para ejemplificar el "realismo español"; esto es, "un modo de conocimiento" desprendido del pensamiento greco-latino-europeo, que no es ni "idealismo" ni "practicismo" y que, alimentado de un "fondo originario" reacio al lógos, ha permanecido "ametódico" y esquivo de la condición teórica propia del racionalismo europeo, "desligado de toda violencia más o menos precursora del apetito de poder". Un modo de conocimiento, por tanto, que es "lo otro que lo llamado teoría" y que es también "un estilo de ver la vida y en consecuencia, de vivirla; una manera de estar plantado en la existencia" (Zambrano, 1987, 34ss), expresada en géneros mayormente ligados al acontecer espontáneo e inmediato de la vida como la literatura o la pintura. $Y$ es también una manera de morir. Al igual que el pueblo movilizado durante la guerra, casi por instinto y sin apenas armas, dispuesto a morir antes que a matar, evocado por la propia Zambrano en la segunda parte de Los intelectuales en el drama de España (1998, 103-127), el descamisado de Goya, cuya humanidad "se vuelca hacia fuera en un gesto pletórico de vida al borde mismo de la muerte (...), tan palpitante, tan rebosante de sangre y de ímpetu (...)", es "el hombre, el hombre íntegro, en carne y hueso, en alma y espíritu, en arrolladora presencia que penetra así en la muerte. El hombre entero, verdadero" (Zambrano, 1987, 37).

"¿Desde cuando no se había muerto con la naturalidad verdadera y verídica con que moría el miliciano?" (Ímaz, 1992, 67s), se pregunta Ímaz no muy lejos de esta constelación zambraniana de símbolos, evocaciones y reflexiones relacionados con el pueblo y la guerra. Esa misma vitalidad palpitante a punto de ser acribillada a pecho descubierto era para él la viva imagen de la democracia republicana, "una democracia en vivo, en carne viva, en busca de su piel. Porque la piel que tenía, la republicana del 31 , se la habian desgarrado brutalmente (...)" (55). La guerra española, decíamos al principio, fue una "lucha civil internacional", pero si también fue una "lucha quijotesca por el hombre universal", ello es debido a que su protagonista sacrificial, el pueblo español, o el pueblo sin más, la afrontó haciendo valer sus fibras más universales. El "hombre entero, verdadero" se encontró, no ya con su gemelo cainita de siempre, tantas veces evocado en la tradición cultural española, sino también con el hombre moderno barbarizado, con el sujeto de una Europa que había renunciado a su proyecto de universalidad, enquistándolo entre los pliegues de un nacionalismo expansivo y beligerante, del fascismo en última instancia. El pueblo descamisado y con la piel en carne viva tuvo así que vérselas con ese hombre moderno, uniformado con camisa parda, negra o azul, como dirá İmaz en algunas ocasiones.

4. Ímaz fue uno de los pocos pensadores del exilio que dedicaron al fascismo una reflexión de cierta enverga- 
dura, más allá de la vicisitud española y al hilo de una cierta crítica de la tradición filosófica moderna. Desde sus colaboraciones en Cruz y raya y Diablo Mundo había seguido de cerca el ascenso y la evolución del fascismo en Europa, retratando algunas de sus expresiones y ademanes, advirtiendo su voracidad biológica y su ciega voluntad de guerra, y trazando algunas hipótesis genealógicas del mismo. Las referencias de İmaz al singular fascismo español son escasas y parcas, pero su ascendencia europea y hegeliana hizo las veces, en este caso, de una especie de "inquisición modernizada". Buena muestra de ello sería un fragmento del libro de José Permantín España como pensamiento (Acción española. Antología. Burgos, 1937), que Ímaz reproduce en "A la luz de la guerra relámpago (2). Fascismo integrista o supertotalitario", y según el cual "El fascismo, el absolutismo hegeliano, no sólo puede y debe darse en España, sino que es España la única nación europea donde cabe en un sentido absoluto; porque nuestro fascismo, nuestro absolutismo hegeliano-jurídico se ha de sustentar necesariamente, como Forma, en una sustancialidad católico-tradicional, es decir, fundamentada en la verdad trascendente" (84). Aun de manera muy puntual, Ímaz señala la particular amalgama entre integrismo católico e idealismo hegeliano que, entre otras, habría inspirado al fascismo español. Es decir, al bagaje tradicionalista más o menos característico del pensamiento reaccionario español, que Ímaz parece dar por descontado, habria que añadir el influjo "modernizador" de un Hegel muy actual, en virtud del cual -apunta Ímaz- se "fascistiza" y "estatistiza" la religión, "haciendo que el totalitarismo sea tan total, absoluto y perfecto que no se le escape ni Dios" (85).

La consumación de todo un proceso de absorción secular de la religión desde las exigencias política moderna sería precisamente la gran clave genealógica del fascismo. En este sentido, "Fascismo integrista o supertotalitario" remite a dos jugosos ensayos de İmaz. "A Dios por razón de Estado", publicado en Cruz y Raya en 1933 (Ímaz, 1988, 37-48) y "En busca de nuestro tiempo", publicado en $R e-$ vista de Occidente en abril de 1936, desatada ya la guerra civil (1988, 134-138), sin olvidar algunos artículos breves como "Concepto de lo político" (1988, 13-17), "La unión de los jóvenes" (1988, 24-27), "Corporativismo y caudillaje" (1988, 49-59), "De Monarquía" (II, 40-44) o "Leviatán" (1988a, 75-81), sugieren, aun de manera sinuosa y fragmentada, una interpretación en esos términos. De Maquiavelo a Mussolini, de Lutero a Hitler, toda una cadencia de ascendencias y herencias, de contrapuntos y complicidades, iría delimitando algunos trazos fundamentales de la política moderna.

Rota la unidad cristiano-medieval del mundo bajo la presión de sus propias contradicciones internas, fragmentada esa misma fe religiosa que la había aglutinado en torno a sí, el des-religado hombre moderno -viene a decir Ímaz- no sabrá donde ni cómo ubicar su propia soberanía. El poder será entonces su gran obsesión, hasta nuestros dias. "El poder en todas sus formas: el poder que Ilaman de mando, el de los políticos; el poder de que gozan los patentados, los ricos; el poder, el dominio sobre la naturaleza que tendrán los técnicos". En la política, el Príncipe de Maquiavelo "está poseído del poder en lugar de ser él quien lo posee. Poseído y creído" (1988, 136s) El poder absoluto y perpetuo del soberano teorizado por Bodino y el iusnaturalismo del XVII irán construyendo un Estado a la manera de una Iglesia laica que encontrará formulaciones álgidas en el Leviatán de Hobbes, modelo de despotismo ilustrado y germen de totalitarismos. Las guerras de religión no han hecho más que reafirmar la llamada de la secularización y de la neutralidad religiosa; pero Hobbes tendrá que recurrir a la fuerza como única manera de asegurar la paz o la felicidad del individuo, ya que la soberanía irreductible de este último, plasmada en el principio de la libertad de conciencia, es fuente de conflicto; en realidad, ha absorbido y metabolizado los fanatismos que habian dado lugar a esas mismas guerras. Se prefigura ya entonces la guerra o el conflicto entre soberanías, cuya justificación intrínseca última no reside sino en el poder que emana de ellas mismas, como esencia schmittiana de lo político. El pacto es entonces la fórmula secular que ha logrado reducir las diversas ciudades de Dios en lucha a una sola ciudad de los hombres en paz, pero a costa del artificio leviatanesco; mismo, por cierto, que Locke y Rousseau sólo quiméricamente habrían logrado desarmar y armar de otra manera, puesto que "la libertad del gobierno democrático liberal, lejos de restituir al hombre su libertad, lo que hace es abandonarle a la libertad de los demás, a la sociedad, que no es otra cosa que el sistema violento de las subordinaciones (...)" (Ímaz, 1988, 138). La fe puritana en el trabajo y la riqueza nacida de la tolerancia religiosa y madurada al hilo del expansionismo imperialista británico; y el dominio técnico sobre el mundo nacida del desencantamiento de la naturaleza inaugurado por Bacon y sistematizado bajo la categoria de progreso a partir de Turgot, entre otras 
referencias cruciales, irán haciendo el resto. Destreza técnica objetivada en la economía, proyección expansiva y justificación inmanente de sí misma en base a la lógica del propio despliegue histórico de la historia, de sí misma: la soberanía moderna se instituye y fortalece, creando ya las condiciones de posibilidad del estado totalitario.

Pero es en el idealismo en donde este proceso secularizador alcanza momentos de síntesis particularmente maduros, bajo el sello del naciente nacionalismo germánico. Los Discursos a la nación alemana de Fichte -apunta Ímaz en "A Dios por razón de Estado"- instituyen "el santo patriotismo alemán" e instauran, en base a él, "todos los fervores de la patria terrenal" previa reducción pagana de la "patria celestial" significada en el cristianismo. Éste último -afirma Ímaz citando a Fichte- identificaría a "la religión del tiempo viejo", lastrada por el "egoísmo" de los débiles, que necesitan el temor y la esperanza en un destino trascendente más allá de este mundo, y frente al cual se erige la "verdadera religión, que nuestra vida vive inmediatamente en Dios", y que "debe dominar en la época moderna" $(1988,44)$. Esta religión moderna, inmediata e inmanente, no es otra que la vida o espíritu del pueblo, expresión de lo eterno en la tierra y cuya afirmación paradigmática recaería en la nación alemana en tanto que "protopueblo" o Urvolk; pues el espíritu alemán "es un águila que trata de acercarse cada vez más al sol, cuya contemplación le embelesa", mientras que el resto de pueblos europeos, "pueblos germánicos romanizados, hablan un idioma que les fue extraño" y piensan valiéndose de "símbolos muertos" (45).

La alusión a la conquista contemplativa del sol no es casual. "A Dios por razón de Estado" se inicia con una referencia a Lutero y su parábola del sol, cuyos rayos -afirma en su polémica con Zwinglio a propósito de la presencia real de Dios en el pan y el vino, según una cita recogida por İmaz- "se hallan tan cerca de ti que están en tus ojos y sobre tu piel. Pero no puedes cogerlos, encerrarlos en una caja por mucho que te esfuerces." Y así el mismísimo Cristo, que "no se deja coger", pero está "ahi para ti cuando da su palabra" -prosigue- y se compromete, diciendo: "Aquí me encontrarás", de manera que "Cuando tengas una palabra semejante podrás con seguridad cogerlo y poseerlo, y decir: aquí te poseo" (38s). Ímaz sugiere así una continuidad entre la libertad luterana de conciencia y su secular nacionalización bajo el idealismo. La interpre- tación "derrotista" del cristianismo planteada por Fichte significará entonces reducción de la trascendencia inscrita en aquella libertad a una inmanencia colectiva y originaria que se exterioriza de manera ilimitada gracias a los resortes espirituales del idealismo. De ahí la naturaleza posesa de la nación alemana. "Fichte no diviniza el Estado, pero sí, a través del espíritu del pueblo, el patriotismo. Ya es bastante".

Hegel hace el resto. Con Hegel, el contenido moral de esa vida espiritual se hace objetivo -y no sólo colectivo, racial o popular- en la medida en que se constituye como Estado. Éste es entonces "la realidad de la idea moral, o, si se quiere más claro, el paso de Dios por el mundo"; o acaso "el mismísimo demonio" (45), pues ese paso mundano exige, no ya el sacrificio del individuo, sino también de todos aquellos pueblos o estados que fracasen ante el tribunal de la historia. Con Hegel, la razón se explica a sí mismo divinizándose, objetivándose en el Estado y realizándose históricamente merced a un autodespliegue dialéctico que reduce a mera apariencia la violencia de sus propios costes. Merced, asimismo, a la interioridad luterana, dicha realización se cumple sólo en aquellos estados que han madurado religiosamente bajo el impulso de la Reforma y que son en consecuencia aptos para ser libres. En los países protestantes "el espíritu empapa inmanentemente lo secular", y esa interioridad, que inicialmente "era una vía de escape al otro mundo, se ha convertido en un camino circular, inmanente, dentro de la conciencia totalitaria del Estado" (145) y de su epifanía en la historia. "El espíritu, por fin, después de un forcejeo dialéctico de milenios, ha llegado, en magnífico orto, a reconocerse a sí mismo como libre, como libertad. La historia, en realidad, ha terminado" (142s). Como en el mito -apunta Ímaz en "En busca de nuestro tiempo"- su último capítulo habría de escribirse "con sangre" (143).

Precisamente a la sombra de Hegel, la escuela histórica e historiadores del Imperio germánico como Heinrich von Treitschke le sacarían todo su jugo al "espíritu del pueblo". Volviendo a "A Dios por razón de Estado", advierte Ímaz la actualidad de Treitschke -además, por supuesto, de dicha escuela y del propio Hegel, sin olvidar la referencia schmittiana- en la Alemania nacional-socialista, particularmente en la efervescencia de sus movimientos político-religiosos. En primer lugar, el de los "cristianos alemanes" o "de raza aria" (39), declarado en abril de 1933 bajo la apelación a 
la misión providencial que está llamado a desempeñar en el momento histórico actual, y cuyas directrices fundamentales propugnan la instauración de "una Iglesia a tono" con la "nueva soberanía del Estado nacional-socialista", frente a las amenazas del "bolchevismo y el anticristiano pacifismo". Según se dice en un boletín oficial del movimiento citado por Ímaz, "un cristianismo positivo, racial, alemán, y que rechaza como extraña la introducción en la Iglesia de conceptos e interpretaciones liberales, aunque se enmascaren con aires de modernidad." (41).

Ahora bien, a la hora de escrutar las relaciones entre religión y política que se van delineando en el horizonte del Tercer Reich, Ímaz no parece fijarse tanto en este movimiento, cuyo perfil integrista es bien simple y obvio -de ahí cierto escepticismo suyo hacia la condena que del mismo hiciera el teólogo Kart Barth-, como en el Ilamado movimiento "acristiano", muy presente en la academia alemana y en la escritura de ese último capítulo de la historia. Acristiano porque, en la "línea pagana" (46) de Fichte y Hegel, aquilatada por un cierto Nietzsche, culminaría la ya mencionada interpretación "derrotista" del cristianismo, absorbiendo su fuerza moral para metabolizarla en una suerte de "religión germánica" (43). Es en este contexto que Ímaz señala la actualidad del historiador nacionalista y antisemita Treitschke, quien en su Politik (1897) justifica la voluntad de poder del Estado, así como su deber moral de preservarla y realizarla, en tanto que ella es la misma expresión de la voluntad de Dios. "Con Treitschke, el Espíritu Santo, La Palabra, es el Poder" (47). Se culmina así, mediante una inversión de los términos, el proceso secularizador abierto por Lutero. Si con su doctrina de la justificación de los actos por la fe el padre de la Reforma había dejado a la conciencia prisionera de la palabra de Dios, ahora ésta "resulta prisionera de la conciencia" (47), es decir, del soberano, entendido -afirma Ímaz a propósito de un discurso reciente de Hitler- como imposición de un señorío que "no debe ser arbitrariedad, sino noble razón" y evidencia moral de las más altas capacidades y los más altos pensamientos; o, sencillamente, como "derecho del más fuerte". La palabra, prisionera entonces "de una camisa. De una camisa de fuerza. De una fuerza de 3.000 .000 de camisas" $(48)^{5}$

5. ¿No hay, entonces, secularización que valga? El humanismo de Ímaz busca precisamente una respuesta afirmativa a esta pregunta. De manera asimismo fragmentada,
Ímaz plantea la necesidad de rescatar y actualizar al "uomo universale" del Renacimiento, el cual, de la mano del utopismo de Moro y de las expectativas secularizadoras del dogma de la redención y materializadoras de la Ciudad de Dios abiertas por el Nuevo Mundo, del cristianismo erasmista y del pacifismo de Vives entre otros, habría arrojado las claves de una modernidad malograda bajo el peso de las razones de estado, el espíritu técnico y el derecho de propiedad. Ímaz, quien desde la órbita ideológica católicorepublicana de Cruz y Raya había permanecido atento al personalismo contemporáneo, traduciendo a autores como Paul Landsberg, quiere reconstruir vínculos entre la religión y la política, de manera que aquella sea piedra de toque de un humanismo universalista y utópico capaz de afrontar la barbarie actual. "Hoy, el hombre universal no es un ideal, sino una necesidad" (1988, 110). De ahí su interés por conceptos de la tradición clásica, reelaborados a partir del Renacimiento, tales como "humanitas", "dignidad del hombre", "hermandad de naturaleza" o "humanización" como "posibilidad de ser todas las cosas" y como ciudadanía de "una república cósmica, no sólo política, que abarca el universo entero" (215). De ahí también su rescate de las posibilidades utópicas de un cierto Kant y hasta un cierto Hegel; y su reivindicación de algunos planteamientos actuales como la crítica religiosa de Albert Schweitzer -a quien denominará nada menos que "hombre del siglo"- o la alteridad judía de Buber. Retoma así Ímaz la célebre pregunta sobre "comment redonner un sens au mot humanisme" que Jean Beaufret había dirigido a Heidegger en 1946, y cuya respuesta, como se adivina, discurrirrá por derroteros bien distantes a los de la autenticidad asoladora y espectral del existencialismo ${ }^{6}$.

Pero, ¿no sería este humanismo el tronco genealógico de las democracias liberales actuales, no en vano enfrentadas al fascismo? La guerra española mostró escandalosamente que no. Para Ímaz, en esta guerra no hubo dos, sino tres beligerancias. Junto al pacifismo militante del pueblo español y la necesidad fascista de la guerra -recordará en 1940- fue asimismo determinante el no-intervencionismo de las democracias occidentales, agria y agudamente denunciado en sus artículos de España peregrina. El fascismo, con su voracidad, había contaminado incluso a las democracias liberales, mismas que, bajo el patrocinio del gobierno británico, intervinieron en la guerra española inhibiéndose ante ella. "¿Qué hemos visto?" -se pregunta Ímaz al respecto haciendo valer su autoridad testimonial. 
"Hemos visto que defendiamos una democracia que ha sido traicionada por las democracias más representativas y traicionada desde un principio, porque la no-intervención es el nombre que le dieron a su intervención esas democracias representativas. $Y$ traicionada no de cualquier manera, sino de la manera más absoluta: haciendo traición a sus propios principios. Porque no hay que olvidar que la no-intervención se estableció, según dijeron ellas, para salvaguardar el derecho, eminentemente democrático, de los pueblos a disponer de sí mismos. Y nosotros, que habíamos dispuesto de nuestras voluntades en unas elecciones, que habiamos dispuesto de nuestras vidas haciendo frente a una rebelión militar, no pudimos disponer de nuestras armas. Con la no-intervención, con su abuso de confianza, hace crisis la democracia europea. Ideológicamente se suicida" $(1992,55)$.

Si antes se desenmascaraba el engaño del intelectual "au dessus de la melée" y apegado a las verdades de cátedra, ahora se denuncia el liberalismo de gabinete y las políticas diseñadas por la alta diplomacia europea. Si la teoría del conocimiento construida por los académicos daba la espalda a los problemas reales del hombre contemporáneo, más aún lo hace la política desplegada por las potencias democráticas europeas. Se reproduce así el engaño del lenguaje. Por eso hay que Ilamar

"voluntarios a los soldados alemanes e italianos. Y no-intervención al bloqueo. Nacionales a los instrumentos del extranjero. A los mata-niños, gentes de orden y a los matricidas, gentes de religión. Todo eso pedía la civilización. Siempre había tiempo para reconsiderar la política a seguir y para negociar con los que no tenían otra consideración negociable que la suya: la guerra. Se negoció la paz y se la puso de precio la generosa sangre española" (68).

Si la verdad de cátedra se desdecía en mentiras, la apelación civilizada a la no beligerancia ante la cuestión española se desdice como complicidad con la guerra; el derecho de gentes, como un "gentlemen's agreement" (1988b, 53) o un reparto interesado de fuerzas bajo la intimidación del fascismo, hasta el punto de devorar ésta, también -dice Ímaz en 1940, en plena expansión europea del nazismo- a los generosos donantes. La guerra española significó así también el suicidio ideológico de la Europa demo-liberal, su claudicación ante una concepción de la política inspirada en la guerra y la dominación. En "Entre dos guerras" (1992, 67-73), ilustraba Ímaz esta denuncia con algunas referencias elocuentes. El reciente libro de E. Dzlepy Espejo de alevosías. Inglaterra en España México, séneca, 1940), algunos informes publicados en el Bulletin Quotidien o algunas declaraciones de la alta diplomacia británica, evidenciaban los resortes del no-intervencionismo: identificación de la legalidad republicana con el caos revolucionario y de la agresión armada contra ella con una "guerra ideológica"; temor ante el auge del Frente Popular en Francia; visión peyorativa de la política española, asociada con lo bárbaro, y, en consecuencia, opción por los representantes del "orden". "No hay más remedio, pues, que abandonar al pueblo español en manos del fascismo. Un pueblo menos, ¿qué importa al mundo? Los franceses, los amigos, encontraron una respuesta consoladora: antes el fascismo que la guerra. Es decir, (...) antes la guerra que la guerra", mientras que "para Inglaterra, la cuestión española no valía la vida de un marinero inglés" (71). En medio de su indignación, Ímaz señalaba así, al hilo de los acontecimientos, algunos de los hechos que la historiografía más reciente ha ido confirmando, precisando y ampliando?:

En primer lugar, que la neutralidad aliada no tenía como fin lo declarado -evitar la intervención extranjera en el conflicto español- sino satisfacer intereses diplomáticos concretos. Especialmente, la política de apaciguamiento en Europa planificada por el gobierno británico, la cual pasaba por un acercamiento estratégico a la Italia fascista y por la victoria de los rebeldes en España. Es decir, se trataba de un acuerdo que no sólo era muy cuestionable en su estricta formulación teórica, a la luz del derecho internacional, sino que además esa formulación era el disfraz ideológico de razones de estado enteramente partidistas. "El gobierno está rezando por la victoria de Franco", anotaba en este sentido en su diario el ayudante de Lord Halifax, secretario del Foreign Office (Moradiellos, 2006, 83).

En segundo lugar, que el acuerdo buscó legitimidad en la difusión de una imagen peyorativa y "barbarizante" de la situación española inmediatamente anterior a la guerra, identificada con el caos revolucionario y el terror bolchevique, hasta el punto de señalar al propio gobierno republicano como principal responsable de la misma. Esta imagen bien podía inhibir la simpatía espontánea de algunos gobiernos -especialmente el de Leon Blum, en un primer nmomento- con la República española, institución legal y democrática al fin y al cabo, agredida además por una rebelión militar de ideología fascista. 
En tercer lugar, que el acuerdo perjudicó doblemente a la República: porque equiparaba a ambos contendientes en términos de legitimidad política, obviando así la condición agresora de uno y la condición agredida de otro; y también -y sobre todo- porque tanto Italia como Alemania siguieron interviniendo en la guerra aun a pesar de ser suscriptores del acuerdo.

Ninguna ascendencia ideológica de las políticas no-intervencionistas más alejada, por tanto, que ese humanismo del que hablaba Ímaz. Incluso habría que preguntarse, más bien, por el parentesco -bastardo o no- de aquellas con el fascismo, a la vista del juego de complicidades que finalmente hizo posible la victoria de Franco. No olvidemos la referencia de Hobbes casi en lo más alto de la genealogía moderna del fascismo esbozada por İmaz, cuyo humanismo, por lo demás, se tornaría imposible justo cuando sus condiciones de posibilidad parecian más cercanas: la capitulación de Hitler no sólo no forzaría la deposición del dictador español, sino que más bien la reforzaria, en vista del nuevo panorama geopolítico y del juego de fuerzas dominante en la Europa de la postguerra. La incipiente política de bloques, la inminencia de la guerra fría y el anticomunismo renovado, terminarian por llevar a la República española a una segunda derrota, esta vez de carácter hermenéutico. El reconocimiento del régimen de Franco a cargo de la ONU, supondría al mismo tiempo una condena de la República exiliada al olvido; a una nueva expulsión en definitiva, esta vez de la legalidad internacional. "El pueblo español" -decía
Ímaz ya en 1940, apenas iniciado su exilio- "vive todavía en el silencio de la opresión, en la sombra de las cárceles o al aire libre de la peregrinación. $Y$ como las potencias que en nombre de la no-intervención no han rectificado sino que, por le contrario, han insistido hasta el fin" -decia, a propósito del acercamiento diplomático británico al régimen franquista y de las políticas francesas de concentración de refugiados españoles- "nosotros seguimos donde estábamos y ellos donde estaban y seguimos siendo, antes que nada y después de todo, hispanófilos a secas, que ya se agotaron nuestras lágrimas" (1992, 73). De nuevo, la neutralidad aliada se sacudía el agobio de su implícita beligerancia a costa de la cuestión española, esta vez con el beneplácito de la nueva superpotencia occidental, presta ya a instalar sus primeras bases militares en la península. Según Ascunce, esta nueva y definitiva derrota, el absurdo repetido de la connivencia entre liberalismo y totalitarismo, la quiebra del espíritu o de la historia misma como proyecto vital y humanizador, tuvieron mucho que ver en el suicidio de Ímaz en 1951, en un hotel de Veracruz (Ascunce, 1991, 207-220). Su hilo de la verdad, ese "hilo de la verdad que teníamos" -había dicho también en 1940 (1992, 57)- gracias al cual sobrevivian las razones que el combate había destruido fáctica pero no hermenéuticamente, había sido definitivamente cortado. Una guerra con no dos sino tres beligerancias, no una sino dos derrotas, era algo lo suficientemente brutal como para agotar todas las lágrimas. La guerra de Eugenio Ímaz contra la guerra sigue así vigente, en la memoria de su exilio.

\section{NOTAS}

Recibido: 17 de marzo de 2008 Aceptado: 23 de abril de 2009
1 Sobre el compromiso del intelectual con la política y la humanización de la cultura, cf. también su ensayo de 1951 "España y la cultura", Ímaz, 1988, III, 199-204.

2 Al ensayo de Schmitt Concepto de lo político dedicó Ímaz, de hecho, una amplia reseña en Cruz y Raya, en 1933, en la que no faltan las alusiones a Hobbes. Cf. Ímaz, 1988, I, 13-17.

cialismo de cabeza" en Cruz y Raya (1988, 28-36, 60-73), a propósito del marxismo cientista que "al profetizar estrangula la historia" $(1988,30)$, y de las contradicciones que ha ido arrojando su revisionismo posterior, creando así una confusión de lo que no se libra el actual socialismo español.

4 Cf. la primera parte, "Un destino soñado" (Zambrano, 1998, 21-263), especialmente el apartado "14 de abril" (237-248).

3 Ímaz dedicó dos artículos críticos al "socialismo desbaratado" y al "so-
5 Esos 3.000.000 de camisas aluden a "los tres millones de luchado- 
res" que "se han organizado como portadores de la dirección política de la nación (alemana: ASC)" (48), según un fragmento de la Filosofía de la sociedad (Madrid, Revista de Occidente, 1933) de Othmar Spann, traducida por el propio Ímaz.

6 Cf. "Topía y utopía" (1988a, 44-68); "Palabras de aniversario" (1988b, 51-55); "Albert Schwitzer: el hombre del siglo" (1988b, 109-113); "¿Qué es el hombre?" (1988b, 133139); "España y la cultura" (1988b, 199-204); "Angeología y humanismo" (1988b, 213-224). Sobre este humanismo, en el que ahora no podemos detenernos mayormente, cf. los trabajos recogidos en Ascunce (comp.), 1990, 151-232; Ímaz, R., 2002.

7 Cf. por ejemplo Moradiellos, 1996 y 2006.

\section{BIBLIOGRAFÍA}

Ascunce, J. A. (comp.) (1990): Eugenio Ímaz: hombre, obra y pensamiento, Madrid, FCE.

- (1991): Topías y utopías de Eugenio Ímaz, Barcelona, Anthropos.

Gaos, J. (1990): Prólogo a "Luz en la caverna. Introducción a la psicología y otros ensayos", en Ascunce, comp. (1990), pp. 121-130.

Ímaz, E. (1988): La fe por la palabra, San Sebastián, Cuadernos Universitarios.

- (1988a): Topía y utopía, San Sebastián, Cuadernos Universitarios.

- (1988b): Luz en la caverna, San Sebastián, Cuadernos Universitarios.

- (1992): En busca de nuestro tiempo, Prólogo de Iñaki Adúriz. San Sebastián, Departamento de Cultura de la Comunidad Autónoma del País Vasco.

Ímaz, R. (2002): "Eugenio Ímaz o la responsabilidad de un intelectual", en
Ascunce, J. A. y Zabala, J. R. (coords.): Eugenio Ímaz. Asedio a un filósofo, San Sebastián, Saturrarán, pp. 253-273.

Moradiellos, E. (1996): La perfidia de Albion. El gobierno de España y la guerra civil española, México, Siglo XXI.

- (2006): "El gobierno británico y la guerra de España: apaciguamiento y no-intervención", en Egido, A. (ed.): La República aislada. ¿Por qué la no intervención?, Historia del Presente, n. ${ }^{\circ}$, pp. $71-86$.

Zambrano, M. (1987): Pensamiento y poesía en la vida española, Madrid, Endymión.

- (1998): Delirio y destino. Los veinte años de una española, Ed. completa y revisada por Rogelio Blanco Martínez y Jesús Moreno Sanz, Madrid, Ramón Areces.

- (2004): La razón en la sombra. Antología crítica, Ed. de Jesús Moreno Sanz, Madrid, Siruela. 